\title{
PERDAS DE SOLO E DISTRIBUIÇÃO DO TAMANHO DAS PARTÍCULAS DO MATERIAL TRANSPORTADO POR EROSÃO HÍDRICA SOB CULTIVO DE CANA-DE- AÇUCAR E PASTAGEM
}

\author{
Edvania Aparecida Corrêa Alves ${ }^{1}$ \\ Isabel Cristina Moraes ${ }^{2}$ \\ Cenira Maria Lupinacci ${ }^{3}$ \\ Sérgio dos Anjos Ferreira Pinto 4
}

\begin{abstract}
Resumo: O objetivo deste artigo foi avaliar as perdas de solo por erosão hídrica em cultivo de cana-de-açúcar e pastagem, com ênfase em eventos pluviométricos de diferentes intensidades. Foram avaliadas a influência da erosividade sobre o tamanho das partículas do material transportado em solos argilosos e arenosos localizados no centro-leste paulista. Foram selecionados 3 eventos erosivos de diferentes intensidades e coletadas, tratadas e quantificadas amostras de 10 parcelas de monitoramento de erosão do solo. Nos solos arenosos as perdas junto às áreas com cana-de-açúcar foram superiores aos limites toleráveis de perdas. Em ambos os tipos de solos observou-se perdas significativas de argila quando da comparação com a textura do solo original. Tais resultados sinalizam que as frações mais reativas dos solos estão sendo removidas e transportadas mais intensamente, indicando que a inadequação do uso da terra associada a ausência de práticas conservacionistas compromete a qualidade dos solos.
\end{abstract}

Palavras-chave: Parcelas de monitoramento de erosão, evento erosivo, granulometria do material erodido.

\section{SOIL LOSSES AND PARTICLE SIZE DISTRIBUTION OF MATERIAL TRANSPORTED BY WATER EROSION IN SUGARCANE AND PARTURE}

Abstract: The objective of this article was to evaluate soil losses due to water erosion in sugarcane cultivation and pasture, with emphasis on rainfall events of different intensities. This work aimed to evaluate the influence of erosivity on the particle size of the material transported by water erosion in clayey and sandy soils, located in the central-east of the state of São Paulo. We selected 3 erosive events of different intensities. For each erosive event, samples from 10 soil erosion monitoring plots were collected, treated and quantified. Losses in sugarcane areas on sandy soils were

\footnotetext{
1 Professora Adjunta junto ao Instituto de Ciências Humanas da Universidade Federal de Pelotas (UFPel). Email: edvania.alves@ufpel.edu.br

${ }^{2}$ Professora Adjunta da Universidade Federal do Recôncavo da Bahia - UFRB, campus de Cruz das Almas (BA). Email: bel.moraes.geo@gmail.com

${ }^{3}$ Professora Associada do Departamento de Geografia e Planejamento Ambiental da Unesp - Campus Rio Claro (SP). Email: cenira.lupinacci@unesp.br

${ }^{4}$ Professor Titular do Departamento de Geografia e Planejamento Ambiental da Unesp - Campus Rio Claro (SP). Email: saf.pinto@unesp.br
} 
higher than the tolerable loss limits. In both types of soils, losses were observed when compared to the original soil texture. Such results indicate that the more reactive fractions of the soils are being removed and transported more intensely, indicating that the inadequacy of land use associated with the absence of conservationist practices compromises the quality of the soils.

Keywords: Erosion monitoring plots, erosion event, granulometry of eroded material.

\section{INTRODUÇÃO}

A erosão hídrica é um dos principais fatores de degradação dos solos no Brasil e no mundo. Estima-se que aproximadamente um terço de todas as terras agricultáveis do globo estejam degradadas, onde as perdas nestas áreas superaram a taxa de 10 milhões de hectares ao ano (YANG et al., 2016). Além de causar danos ambientais, como o assoreamento, a erosão hídrica reduz potencialmente a capacidade produtiva dos solos (COGO et al., 2003). Sendo o solo um elemento importante para o equilíbrio do meio ambiente e um recurso essencial na produção de alimentos, tem-se que a erosão hídrica é um dos maiores e mais graves problemas ambientais mundiais (GARCIA RUIZ et al., 2015; KIANI-HARCHEGANI et al., 2017; CORRÊA et al., 2018).

No Brasil, estimam-se perdas em torno de 600 milhões de toneladas de solo agricultável por ano e, no estado de São Paulo, tal perda é estimada em 194 milhões de toneladas por ano (VEIGA FILHO et al., 1992). Alguns cultivos têm se expandido no estado de São Paulo, destacando-se a cana-de-açúcar. Nas últimas décadas, o território paulista apresentou o maior crescimento produtivo do país, sendo responsável por mais de 50\% da área plantada com cana-de-açúcar no ano de 2013. Entre 1995 e 2013, a expansão canavieira coincidiu com a redução das áreas de pastagem. Apesar do incremento das áreas cultivadas por cana, a produtividade sucroalcooleira não apresentou a mesma tendência, sofrendo decréscimos (CAMARA et al., 2016). Corrêa (2016) e Corrêa et al. (2018) observaram que em muitas áreas, cujo cultivo de cana-de-açúcar substituiu áreas de pastagem, as perdas de solos foram superiores aos limites toleráveis de perdas, acarretando no rápido depauperamento dos solos. Assim, importância deve ser dada aos estudos que visem avaliar os impactos da dinâmica do uso da terra nos recursos naturais, como o solo.

Além da quantificação das perdas de solo nos diversos tipos de uso da terra e em diferentes unidades de solo, o conhecimento em termos de qualificação do material erodido pode auxiliar na compreensão da dinâmica erosiva bem como dos impactos negativas potenciais ao meio ambiente e à economia. Ademais, tal conhecimento pode auxiliar na validação e adequação dos modelos preditivos de perdas de solo aplicados aos cenários tropicais (GARCIA RUIZ et al., 2015)

No processo de erosão hídrica, de todas as frações dos solos, a areia fina e muito fina, juntamente com as frações de silte, são as mais susceptíveis aos processos de destacamento e transporte. Enquanto as frações areia grossa resistem à mobilização, as frações argila resistem aos processos de destacamento pelas gotas de chuva, pela maior capacidade de agregação (MEYER e HARMON, 1984; DENARDIN, 1990; KIANI-HARCHEGANI et al., 2017).

Existe, assim, uma seletividade no processo erosivo, sendo preferencialmente transportados os sedimentos mais finos e leves os quais são constituídos basicamente por colóides minerais e orgânicos enriquecidos de nutrientes (BERTOL et al., 2007; WARRINGTON et al., 2009; MARTINEZ-MENA et al., 1999; POLYAKOV e LAL, 2004; 
ZHANG et al., 2011; LI e PANG, 2014). Tendo em vista que os colóides minerais e orgânicos são as frações de maior reatividade do solo, parte das frações de maior importância são facilmente destacadas pelas gotas de chuva e transportadas pelo escoamento superficial. Como consequências, tem-se a perda da capacidade produtiva, mudança textural dos solos (SUZUKI et al., 2012) e erosão hídrica acelerada decorrentes da menor densidade da cobertura vegetal. Por outro lado, a perda predominante de colóides do solo também propicia a perda de parte de constituintes químicos dos fertilizantes aplicados, os quais são facilmente carreados para os cursos d'água e afetam a qualidade dos corpos hídricos (RODRIGO-COMINO et al., 2019; KIANI-HARCHEGANI et al. 2017; FOSTER et al., 1985; CASSOL et al., 2002 e NUNES e CASSOL, 2011).

No entanto, a granulometria do material erodido também é alterada a depender da severidade da erosão instalada no terreno. Nos locais com ocorrência de erosão em sulcos, alguns autores observaram que as partículas grossas constituíam as frações de maior predomínio no material erodido, demonstrando que há diferenças nos mecanismos de descolamento e transporte a depender das características físicas da paisagem estudada (SCHIETTECATTE et al., 2008; WANG e SHI, 2015). Também, a granulometria dos sedimentos oriundos dos processos erosivos apresenta elevada correlação com a textura dos solos originais.

Neste contexto, muitos são os fatores que determinam a seletividade do tamanho das partículas removidas e transportadas pela erosão hídrica. Volk e Cogo (2009), Hatfield (2000), Mohammadkhan et al. (2011), Warrington et al. (2009), KianiHarchegani et al. (2017) destacam fatores como declividade do terreno, intensidade da chuva e da enxurrada a esta associada, severidade da erosão (laminar, sulco ou voçorocamento), cobertura, uso e manejo da terra, rugosidade superficial resultante do preparo da terra e características físico-químicas dos solos (destacando-se a estabilidade dos agregados e granulometria).

Diversos autores relacionaram a granulometria dos sedimentos oriundos do processo de erosão hídrica do solo com as características físicas dos solos e manejo. Dentre os principais, tem-se aqueles desenvolvidos por Foster et al. (1981), Meyer et al. (1980), Meyer e Harmon (1984), Foster et al. (1985), Martinez-Mena et al. (1999), Cassol et al. (2002), Bertol et al. (2007), Warrington et al. (2009), Kiani-Harchegani et al. (2017) e Sadeghi et al. (2017). No cenário atual nacional, também há estudos que objetivam avaliar a granulometria do material erodido, como aqueles desenvolvidos por Falcão Sobrinho e Falcão (2005), Suzuki et al. (2012) e Nunes e Cassol (2011).

Alguns estudos têm indicado que eventos chuvosos de grande intensidade são os maiores responsáveis pelas perdas totais de solos (MANO et al., 2009; ESTRANY et al., 2010) e por $50 \%$ das perdas totais de nutrientes em campos agrícolas (GAO et al., 2005). Inúmeros trabalhos têm alertado sobre a maior frequência de eventos extremos de chuvas nos próximos anos em escala global (EASTERLING et al., 2000; GROISMAN et al., 2005), e alguns modelos indicam maiores períodos de estiagem e chuvas de maior intensidade na região sudeste do Brasil (TAVARES, 2004). Assim, avaliar o comportamento erosivo em diferentes eventos chuvosos (e extremos) reflete diretamente na compreensão da dinâmica hidrológica e erosiva dos solos (NUNES e CASSOL, 2011), e consequentemente, das perdas de solo em campos agrícolas.

Neste sentido, o objetivo do artigo foi avaliar a influência de diferentes intensidades de eventos pluviométricos, e, portanto, de erosividade desses eventos, sobre o tamanho das partículas do material transportado por erosão hídrica. Paralelamente, analisou-se também a influência do cultivo de cana-de-açúcar e pastagens no total de perdas de solo, sobre diferentes tipos de solos. 


\section{CARACTERIZAÇÃO DAS ÁREAS DE ESTUDO}

O estudo foi realizado nas bacias hidrográficas do ribeirão do Jacutinga (BHJ) e do córrego Monjolo Grande (BHMG), sendo a primeira localizada nos municípios de Rio Claro e Corumbataí (SP) e a segunda no município de Ipeúna (SP) (Figura 1).

Figura 1. Localização da área de estudo.

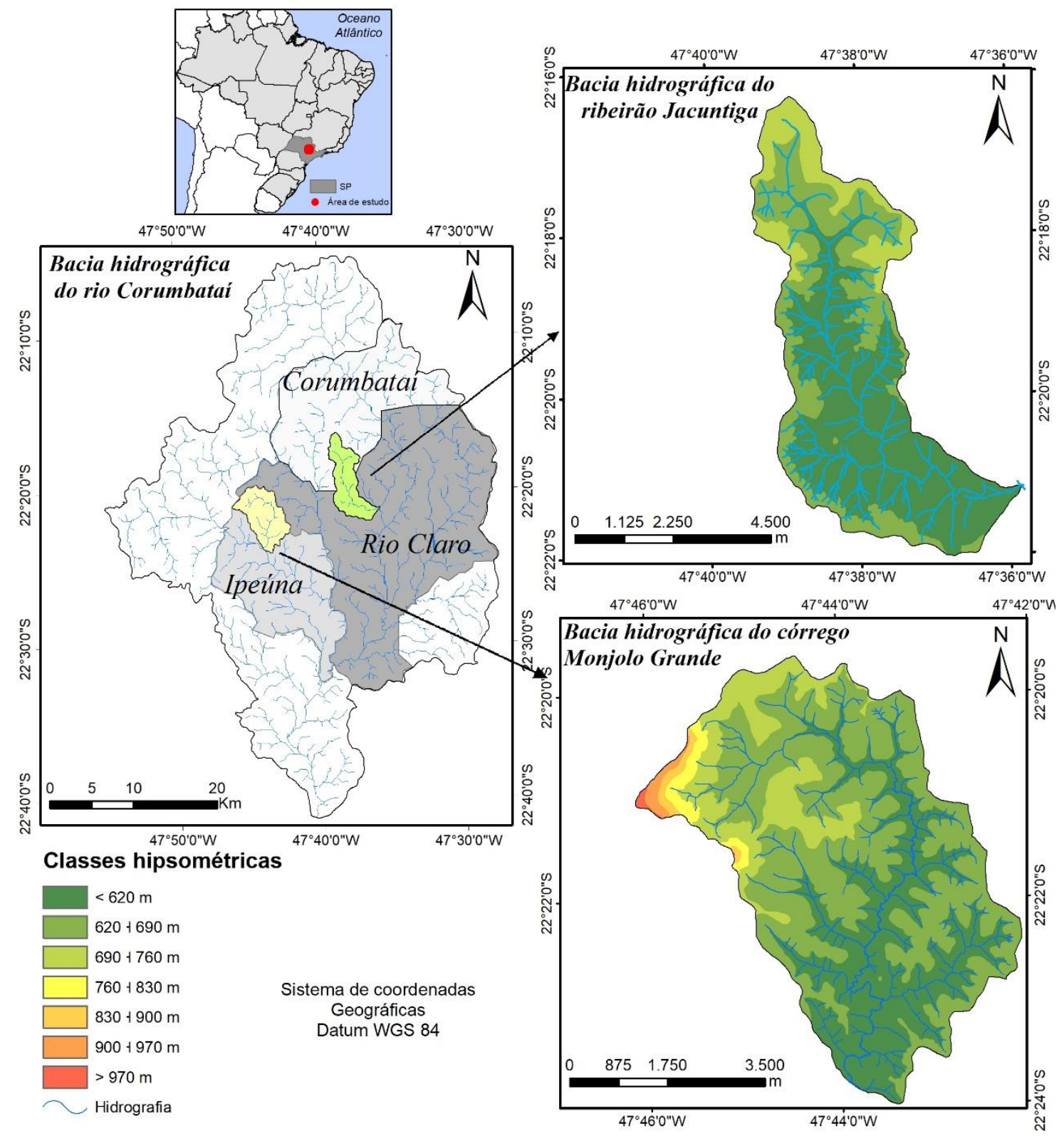

Fonte: Elaborado pelos autores

As áreas de estudo apresentam clima subtropical, com verão chuvoso e inverno seco, sendo o clima classificado como Cwa, conforme a classificação zonal de Köppen. Estão inseridas na província geomorfológica denominada Depressão Periférica Paulista e apresentam topografia pouco acidentada (PENTEADO, 1976; IPT, 1981 e 1999). O relevo é formado, predominantemente, por colinas, com topos aplainados e interflúvios com áreas de 1 a $4 \mathrm{~km}^{2}$. As bordas ocidentais da BHMG, por estarem inseridas nas proximidades do front das cuestas arenito basáltica, 
apresentam pequenos morros residuais com altitudes alcançando a cota de 900 metros, vertentes de alta declividade e drenagem densa e entalhada (Figura 1).

A BHMG compreende área aproximada de $28 \mathrm{~km}^{2}$ e apresenta solos predominantemente arenosos originados dos arenitos das formações Botucatu e Pirambóia. Corrêa (2016) e Moraes (2016) observaram que há o predomínio de Neossolos Quartzarênico junto as áreas de topo e de Argissolo Vermelho Amarelo nas baixas e médias vertentes com declividades inferiores a $20 \%$. Os Neossolos Litólicos foram observados nos locais com declives acima de $20 \%$ e localizados ao longo de vertentes que drenam para canais de $1^{\circ}$ ordem e próximos ao front das cuestas arenito basáltica.

$\mathrm{Na} \mathrm{BHJ}$, com área aproximada de $28,9 \mathrm{~km}^{2}$, tem-se o predomínio de Argissolos Vermelho Amarelos e Cambissolos Háplicos, textura predominantemente argilosa, ocorrentes junto ao médio e baixo curso e originados a partir dos argilitos da Formação Corumbataí. No alto curso da BHJ, e tendo como material de origem os arenitos de granulação fina e média da Formação Pirambóia, tem-se a ocorrência dos Neossolos Quartzarênicos (CORRÊA, 2016; MORAES, 2016).

Ambas as áreas de estudo estão sendo submetidas à intensa ocupação antrópica resultante, principalmente, da expansão dos cultivos de cana-de-açúcar em antigas áreas de pastagens (PEREIRA e PINTO, 2007). Alguns estudos têm demonstrado que a expansão dos cultivos de cana-de-açúcar ocorre junto às áreas que apresentam elevada susceptibilidade a erosão, ocasionando o rápido depauperamento dos solos (CORREA, et al. 2018; CORRÊA, et al., 2015).

\section{MATERIAIS E MÉTODOS}

Foram instaladas 10 parcelas de monitoramento de erosão do solo de $20 \mathrm{~m}^{2}$ (2,00 x 10,00 metros) obedecendo o sentido do declive, sendo 5 em cada bacia hidrográfica (Tabela 1). As parcelas foram delimitadas por chapas galvanizadas de 40 $\mathrm{cm}$ de altura, sendo $10 \mathrm{~cm}$ enterrados no solo e $30 \mathrm{~cm}$ acima da superfície. Foram usadas as calhas de Gerlach (GUERRA, 2005) e tanques armazenadores de água com capacidade de 240 litros (Figuras 2A, 2B e 2C).

Tabela 1. Características das parcelas de monitoramento de erosão.

\begin{tabular}{|c|c|c|c|c|}
\hline $\mathrm{BH}$ & Parcela & $\begin{array}{c}\text { Cobertura } \\
\text { vegetal }\end{array}$ & $\begin{array}{c}\text { Declividade } \\
(\%)\end{array}$ & Solos \\
\hline & $\mathrm{C} 1 \mathrm{M}$ & $\begin{array}{l}\text { Cana-de- } \\
\text { açúcar }\end{array}$ & $12 \%$ & $\begin{array}{l}\text { Cambissolo háplico, Ta eutrófico, } \\
\text { típico, A moderado, textura franco }\end{array}$ \\
\hline Córrego & S1M & $\begin{array}{c}\text { Solo } \\
\text { descoberto }\end{array}$ & $12 \%$ & $\begin{array}{c}\text { arenosa, relevo ondulado a forte } \\
\text { ondulado. }\end{array}$ \\
\hline \multirow[t]{3}{*}{$\begin{array}{l}\text { Monjolo } \\
\text { Grande }\end{array}$} & P1M & Pastagem & $12 \%$ & $\begin{array}{l}\text { Cambissolo háplico distrófico a } \\
\text { moderado, textura franco arenosa, } \\
\text { relevo ondulado a forte ondulado. }\end{array}$ \\
\hline & C2M & $\begin{array}{l}\text { Cana-de- } \\
\text { açúcar }\end{array}$ & $15 \%$ & \multirow{2}{*}{$\begin{array}{l}\text { Cambissolo háplico, Ta distrófico, } \\
\text { típico, A moderado, textura areia } \\
\text { franca/franco arenosa, relevo } \\
\text { ondulado a forte ondulado. }\end{array}$} \\
\hline & S2M & $\begin{array}{c}\text { Solo } \\
\text { descoberto }\end{array}$ & $15 \%$ & \\
\hline \multirow[b]{2}{*}{ Ribeirão } & C1J & Cana-de- & $5 \%$ & \multirow{2}{*}{$\begin{array}{l}\text { Argissolo Vermelho Amarelo, Ta } \\
\text { eutrófico, textura argilosa, A } \\
\text { moderado, relevo suave ondulado. }\end{array}$} \\
\hline & S1J & $\begin{array}{c}\text { Solo } \\
\text { descoberto }\end{array}$ & $5 \%$ & \\
\hline
\end{tabular}




\begin{tabular}{|c|c|c|c|c|}
\hline \multirow[t]{2}{*}{ Jacutinga } & P1J & Pastagem & $5 \%$ & $\begin{array}{l}\text { Argissolo Vermelho Amarelo, Ta } \\
\text { eutrófico, textura argilosa, A } \\
\text { moderado, relevo suave ondulado. }\end{array}$ \\
\hline & $\mathrm{C} 2 \mathrm{~J}$ & $\begin{array}{l}\text { Cana-de- } \\
\text { açúcar } \\
\text { Solo } \\
\text { descoberto }\end{array}$ & $11 \%$ & $\begin{array}{l}\text { Cambissolo háplico, eutrófico, } \\
\text { típico, A moderado, textura argilosa, } \\
\text { relevo ondulado. }\end{array}$ \\
\hline
\end{tabular}

Fonte: Elaborado pelos autores

Figura 2. (A) Parcelas de monitoramento de erosão em solo descoberto (S2J) imediatamente ao lado da parcela de cultura de cana-de-açúcar (C2J); (B) Parcelas de monitoramento de erosão em pastagem (P1M); (C) Calha Gerlach (C2M).
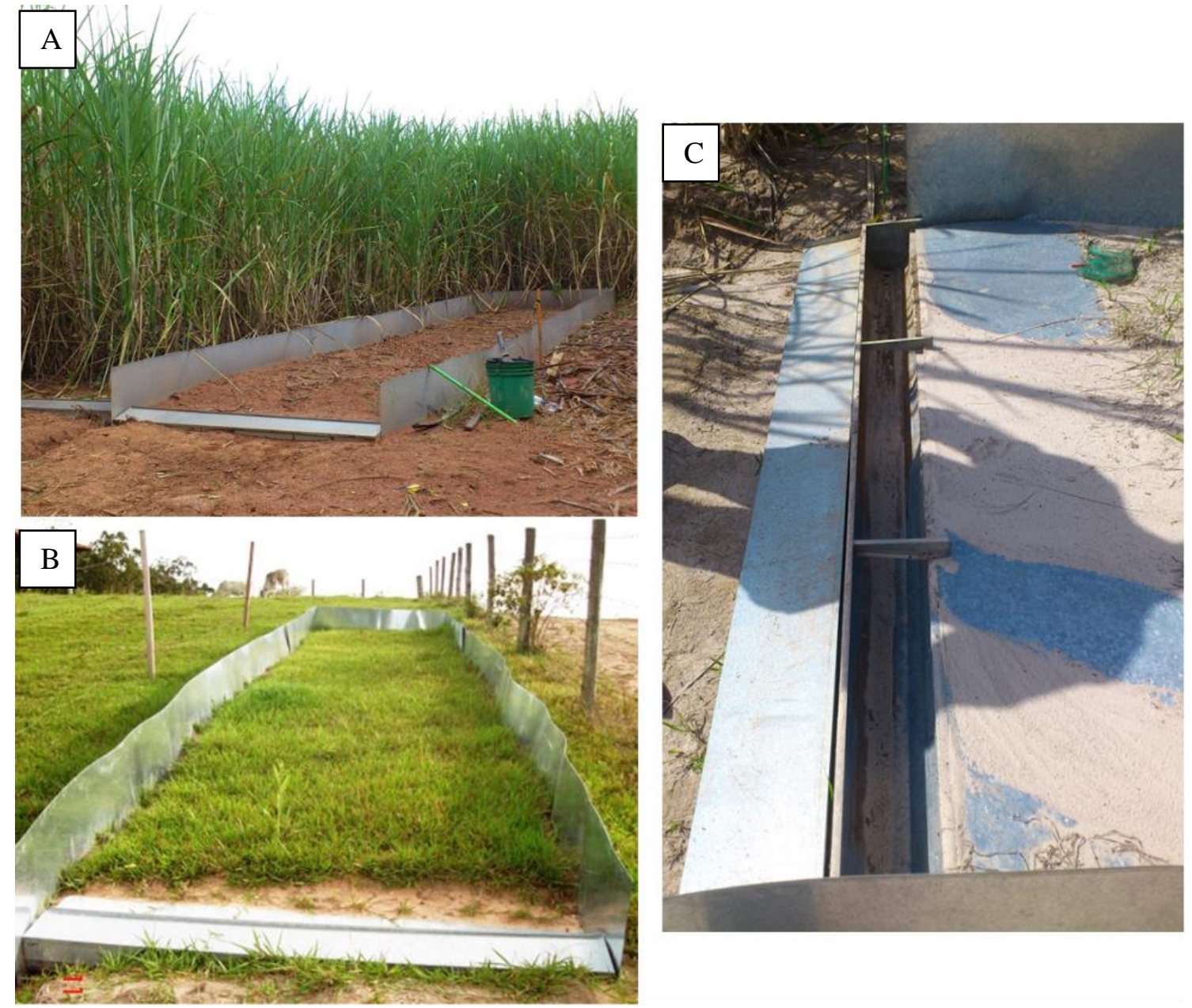

Fonte: Arquivo dos autores

Junto às áreas com cana-de-açúcar de ambas as áreas de estudo foi utilizado o sistema convencional de preparo de solo e as parcelas foram instaladas após o plantio e/ou colheita. $\mathrm{Na} \mathrm{BHJ}$ as parcelas foram compostas por cana-de-açúcar de variedade de ciclo médio, $3^{\circ}$ colheita, sendo a última colheita realizada mecanicamente em 02/06/2013. Foram mantidos os restos vegetais e o plantio em nível e a construção de terraços foram as práticas conservacionistas adotadas. $\mathrm{Na}$ BHMG as parcelas foram compostas por cana-de-açúcar de ciclo médio, as quais foram plantadas em 22/07/2013 após a reforma dos talhões. Devido às condições de declividade, a colheita anterior foi realizada manualmente e não foram mantidos os 
restos vegetais. Como práticas conservacionistas, foram realizados o plantio em curva de nível, construção de terraços e o direcionamento de água dos caminhos para os terraços.

Ao lado de cada parcela com cana-de-açúcar, foram instaladas parcelas desprovidas de vegetação visando à comparação da dinâmica do processo erosivo entre as diferentes condições de cobertura (Figura 2A). Junto às áreas de pastagens extensivas, uso recorrente nas áreas de estudo, foram instaladas parcelas de monitoramento de erosão sendo observada a aplicação do controle da taxa de lotação como prática conservacionista.

O monitoramento de perdas de solo nas parcelas experimentais foi realizado pelo período aproximado de 12 meses. Após cada evento erosivo, foram coletadas amostras de água e sedimentos (COGO, 1978; CORREA et al., 2018), as quais foram secas e quantificadas conforme método da evaporação (CARVALHO et al., 2000). Posteriormente, foram estimadas as perdas considerando o volume total de água presente no interior dos tanques coletores. As perdas totais de solos foram comparadas com os limites toleráveis de cada unidade de solo, conforme Corrêa (2016).

Após a secagem e quantificação das perdas, foram selecionados 3 eventos pluviométricos representativos de chuvas com diferentes erosividades e que ocorreram em ambas as áreas de estudo. Para cada evento selecionado, foram identificadas as amostras de sedimentos coletadas e realizadas análises granulométricas pelo método da Pipeta, utilizando como dispersante $\mathrm{NaOH} 1 \mathrm{~mol} \mathrm{~L}^{-1}$ e agitação lenta por 16 horas (EMBRAPA, 1997).

Para a seleção dos eventos pluviométricos e cálculo da erosividade anual, foram coletados dados (a cada 5 minutos) a partir de estação meteorológica (modelo Davis Vantage Pro 2 Plus) instalada na bacia hidrográfica do Ribeirão Monjolo Grande e do posto pluviográfico D4-112 pertencente ao Departamento de Águas e Energia Elétrica (DAEE) do governo do estado de São Paulo, próximo aproximadamente 10 $\mathrm{km}$ da bacia hidrográfica do ribeirão Jacutinga.

Para cada um dos 3 eventos selecionados, e definidos conforme Wischmeier (1959), Lombardi Neto (1977) e Cabeda (1976), foram obtidos os valores de energia das gotas de chuva (BERTONI e LOMBARDI NETO, 2010):

$$
E_{c}=0,119+0,0873 \log I
$$

Sendo:

$\mathrm{E}_{\mathrm{c}}=$ energia cinética em Megajoule/ha-mm;

$\mathrm{I}$ = intensidade da chuva em $\mathrm{mm} / \mathrm{h}$.

Para cada chuva erosiva, foi determinada a intensidade máxima em 30 minutos (I30), conforme Wischmeier e Smith (1978). O índice de erosividade de cada evento selecionado foi obtido a partir da formulação proposta por Bertoni e Lombardi Neto (2010), onde:

$$
E I_{30}=E c \quad \times I_{30}
$$

Sendo:

$\mathrm{El}_{30}=$ índice de erosão em MJ/ha.mm/h;

$\mathrm{Ec}=$ energia cinética da chuva;

$I_{30}=$ intensidade máxima em 30 minutos $(\mathrm{mm} / \mathrm{h})$.

Para a obtenção dos valores de erosividade anual, foi realizada a soma das erosividades de todos os eventos erosivos de cada área de estudo. 
A fim de caracterizar fisicamente os solos, em cada parcela de monitoramento foram realizadas sondagens com trado e coletadas amostras de solo nas profundidades de 0 a $60 \mathrm{~cm}$ (EMBRAPA,1997). Foram realizadas as análises granulométricas pelo método da Pipeta (EMBRAPA, 1997). Os solos foram classificados de acordo com o Sistema Brasileiro de Classificação dos Solos (SANTOS et al., 2018), em nível de Subgrupo (3ํㅡível), mais grupamento textural.

\section{RESULTADOS}

A erosividade anual foi de 4546,89 $\mathrm{MJ} \mathrm{mm} \mathrm{ha}^{-1} \mathrm{ano}^{-1}$ na BHMG e de 2621,08

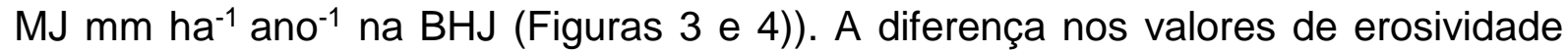
entre as áreas de estudo se deve ao efeito orográfico associado ao relevo de cuestas sobre a BHMG. Assim, verifica-se maior quantidade de precipitações e, consequentemente, maior atuação do potencial erosivo das chuvas junto aos solos arenosos da BHMG. Os eventos erosivos selecionados foram em: 23/11/13, 01/03/14 e 11/04/14, os quais apresentaram erosividade de 488,9, 276,1 e 397,8 MJ mm ha-1 ano $^{-1}$ na BHMG, respectivamente (Figura 3). Já na BHJ, a erosividade foi de $488,9 \mathrm{~mm}$ ha $^{-1}$ ano-1 $^{-1}$ para o evento de $23 / 11 / 13$, de $179,8 \mathrm{MJ} \mathrm{mm} \mathrm{ha}^{-1} \mathrm{ano}^{-1}$ para o evento de 01/03/14 e de 39,4 MJ mm ha-1 ano-1 para o evento de 11/04/14 (Figura 4).

Figura 3. Granulometria do material erodido nas parcelas em solos arenosos da BHMG

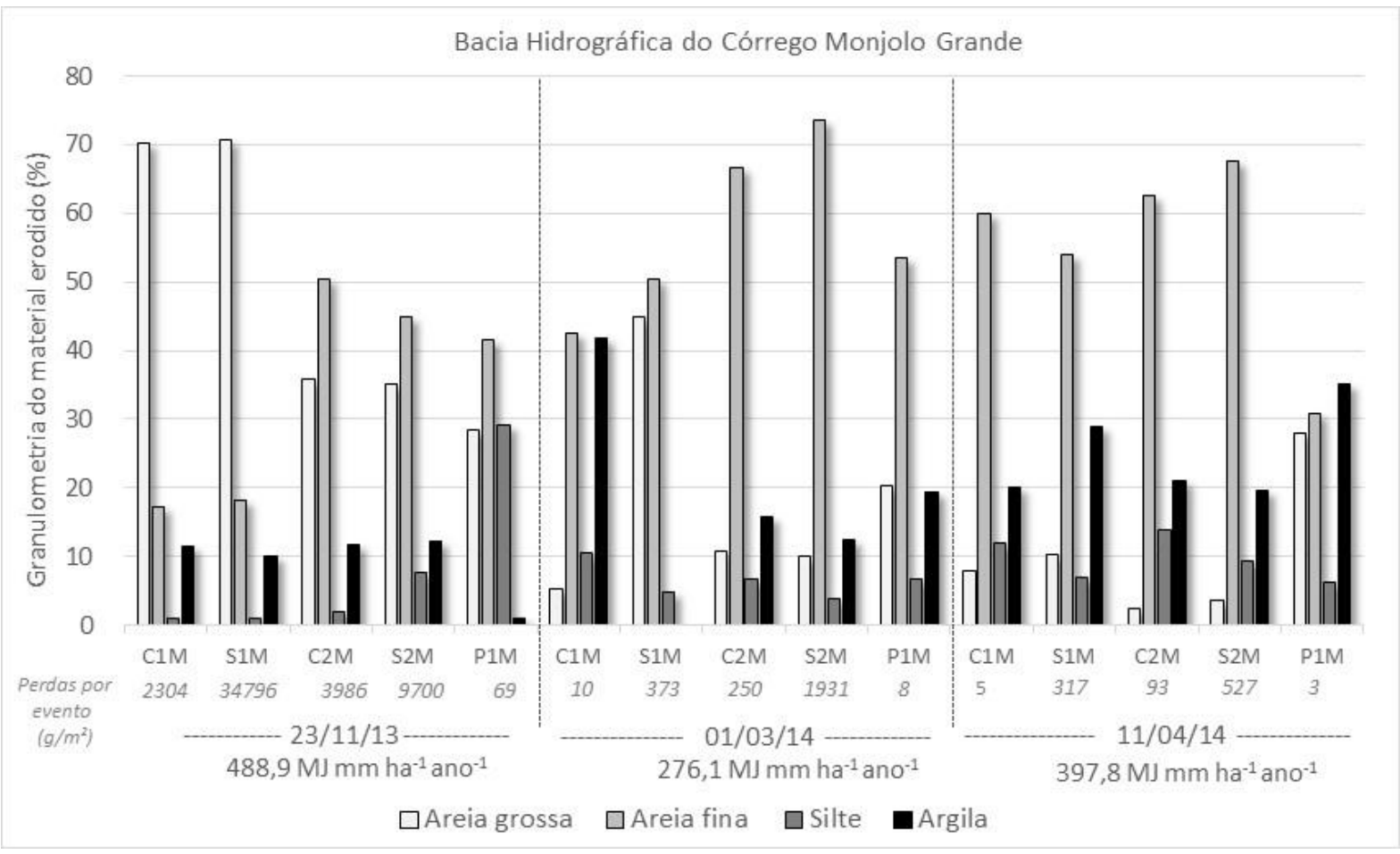

Fonte: Elaborado pelos autores 
Figura 4. Granulometria do material erodido nas parcelas em solos argilosos da BHJ

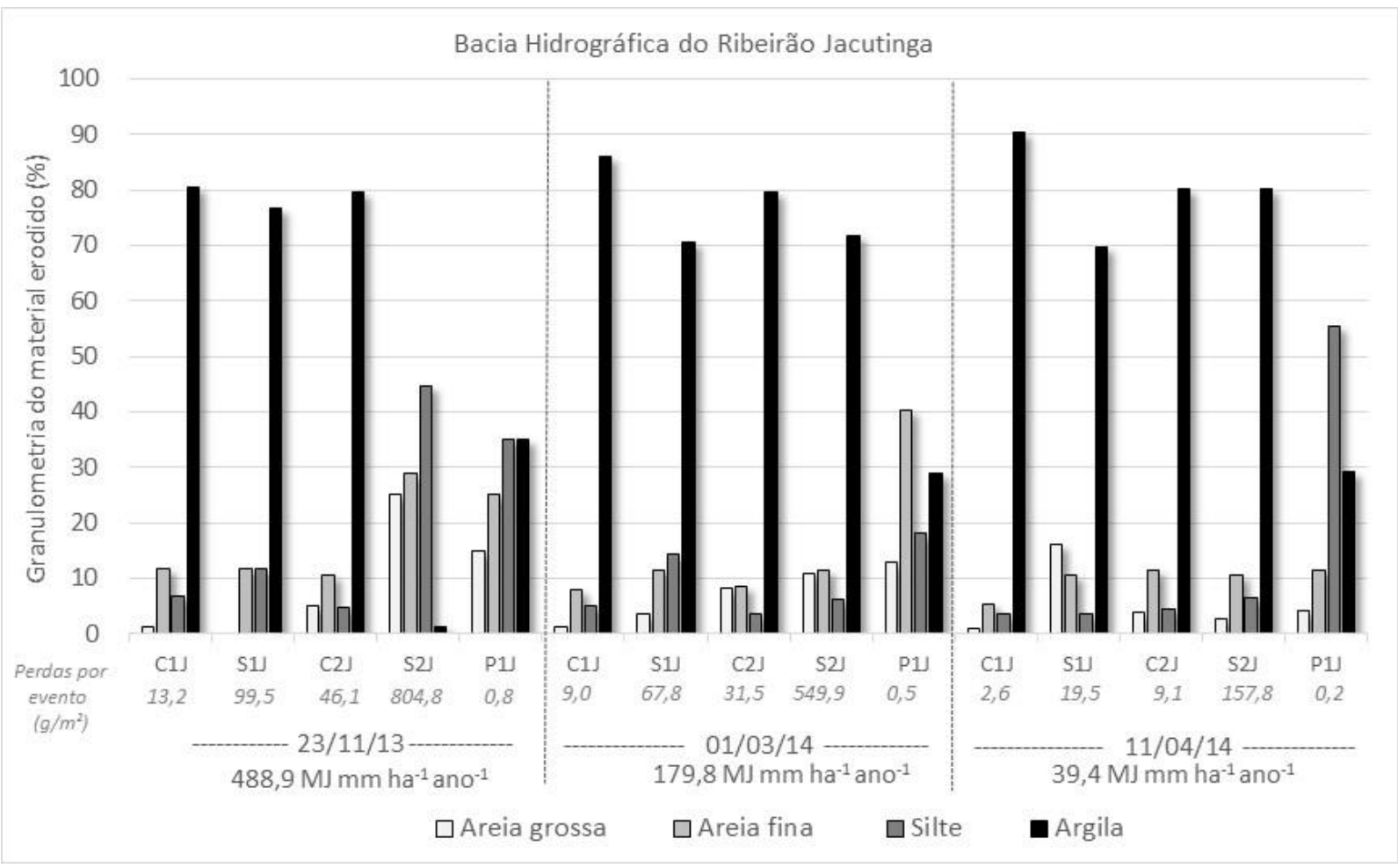

Fonte: Elaborado pelos autores

No que se refere a granulometria do material erodido, as parcelas S1J, S2J, $\mathrm{C} 1 \mathrm{~J}$ e $\mathrm{C} 2 \mathrm{~J}$ dos solos argilosos da $\mathrm{BHJ}$ apresentaram perdas predominantes de argila (Figura 4). Asadi et al. (2007) demonstraram que em solos coesos e bem estruturados, as perdas são predominantes de partículas finas. Também Jin et al. (2009) verificaram alta mobilização de partículas mais finas em um solo argiloso com $75 \%$ de cobertura de superfície com chuvas de 65, 85 e $105 \mathrm{~mm} \mathrm{~h}^{-1}$. Nunes e Cassol (2011) também relataram que a granulometria dos sedimentos oriundos dos processos erosivos apresenta elevada correlação com a textura dos solos originais (Tabela 2). Neste sentido, devido a maior coesão e estrutura dos solos da BHJ bem como a textura predominantemente argilosa, tem-se maiores perdas predominantes de frações de argila, as quais são as partículas de maior reatividade do solo.

Tabela 2. Distribuição das frações granulométricas nos solos nas parcelas experimentais.

\begin{tabular}{cccccc}
\hline Parcelas & Prof. & $\begin{array}{c}\text { Areia } \\
\text { Grossa }\end{array}$ & $\begin{array}{c}\text { Areia } \\
\text { Fina }\end{array}$ & Silte & Argila \\
\hline & cm & \multicolumn{2}{c}{$-----------------\%$} & ------------- \\
\hline \multirow{2}{*}{ C1M e } & $0-20$ & 23,4 & 55,2 & 5,5 & 16 \\
S1M & $20-40$ & 25,2 & 52,2 & 4,5 & 18,2 \\
& $40-60$ & 26,3 & 48,7 & 4,2 & 20,8 \\
\hline \multirow{2}{*}{ C2M e } & $0-20$ & 10,6 & 80,3 & 5,2 & 4 \\
S2M & $20-40$ & 8,5 & 66,1 & 2,4 & 23 \\
& $40-60$ & 8,9 & 63,4 & 3,4 & 24,3 \\
\hline \multirow{2}{*}{ P1M } & $0-20$ & 25,1 & 54,1 & 1,6 & 19,3 \\
& $20-40$ & 33,5 & 46,5 & 2,4 & 17,7
\end{tabular}




\begin{tabular}{cccccc} 
& $40-60$ & 32,8 & 47,5 & 2,9 & 16,8 \\
\hline \multirow{3}{*}{ C1J e S1J } & $0-20$ & 13,5 & 22,1 & 15,1 & 49,3 \\
& $20-40$ & 15 & 13,1 & 13,6 & 58,4 \\
& $40-60$ & 8,3 & 10,8 & 9,1 & 71,8 \\
\hline \multirow{3}{*}{ C2J e S2J } & $0-20$ & 9,5 & 14 & 35,3 & 41,3 \\
& $20-40$ & 15 & 8,8 & 34 & 42,3 \\
& $40-60$ & 16,2 & 6,5 & 36,3 & 41 \\
\hline \multirow{2}{*}{ P1J } & $0-20$ & 13,5 & 28 & 16,7 & 41,9 \\
& $20-40$ & 8,2 & 18,9 & 17,9 & 55,1 \\
& $40-60$ & 6,3 & 16,8 & 13,5 & 63,4 \\
\hline
\end{tabular}

Fonte: Elaborado pelos autores

As parcelas cobertas por cana-de-açúcar (C1J e C2J) e a parcela com solo exposto (S1J) apresentaram comportamento semelhante, em termos da granulometria do material erodido (Figura 4), sendo observado nos 3 eventos erosivos avaliados. Porém, perdas superiores de silte, areia fina e areia grossa ao invés de argila foram observadas na parcela sem cobertura vegetal S2J, no evento de $23 / 11 / 13$. O maior evento erosivo avaliado na BHJ, de $488,9 \mathrm{MJ} \mathrm{mm} \mathrm{ha}^{-1}$ ano $^{-1}$, foi forte o suficiente para deslocar o material arenoso, demonstrando que episódios de elevada erosividade tem maior potencial a perdas de materiais mais grossos que as frações predominantes no solo original, especialmente em solos argilosos (tabela 2). Além de S2J situar-se na classe de Cambissolo háplico, de textura argilosa, o maior declive avaliado (11\%) e a ausência de cobertura vegetal corroboraram para tal comportamento.

As parcelas com gramíneas apresentaram as menores perdas em ambas as áreas de estudo (tabela 3). Junto a estas parcelas (P1M e P1J) verificou-se que não houve relação entre a erosividade e a granulometria do material erodido. Na parcela P1J verificou-se que, em todos os eventos erosivos, as perdas foram compostas por sedimentos de diâmetros maiores do que aqueles dominantes no solo original. Assim, tanto em função do pouco revolvimento do solo vinculado ao uso com pastagens extensivas durante muitos anos, quanto pela própria cobertura promovida pelas gramíneas, as argilas nas parcelas de pastagem se mostram mais estáveis e agregadas. Já na parcela P1M nota-se que as perdas de solo são compostas predominantemente por frações de areia grossa e fina.

Quanto à análise granulométrica do material erodido nas parcelas de solos arenosos da BHMG, nota-se que em eventos de elevada erosividade como o de 23/11/13, as frações perdidas de solo foram majoritariamente de areia grossa e areia fina (Figura 3). Esse comportamento altera-se com a diminuição da erosividade dos eventos, onde a granulometria dos materiais erodidos passa a ter relação mais direta com a textura do solo (tabela 2). Neste sentido, nos eventos erosivos de 01/03 e 11/04, prevaleceram as perdas de areia fina, fração predominante nos solos de todas as parcelas localizadas na BHMG (tabela 3).

Além da maior capacidade erosiva do evento pluviométrico de 23/11/2013, a ausência ou baixa cobertura vegetal favoreceu maior mobilidade de material mais grosseiro, como a areia grossa, especialmente nas parcelas situadas em declividades acima de $6 \%$. Em geral, nos eventos erosivos subsequentes, há o domínio das perdas de areia fina, e progressivamente, de silte e argila. Os ciclos de plantio e colheita da cana-de-açúcar afetam a dinâmica da cobertura de superfície, e acarretam a ausência ou baixa cobertura vegetal durante a entressafra e mesmo nos primeiros meses de 
plantio, o que não ocorre nas parcelas instaladas em pastagem. Este fato é evidenciado ao se verificar que no primeiro evento erosivo na BHMG, em 23/11/13, destacam-se as perdas de areia grossa, e também areia fina. No terceiro evento erosivo, quando a cana-de-açúcar se encontra mais desenvolvida, mesmo com valores próximos de erosividade ao primeiro evento, há o predomínio de areia fina, e maiores perdas de silte e argila.

A relação dos materiais erodidos com a erosividade corrobora com o observado por Feng et al. (2015). Os autores avaliaram a granulometria do material erodido em parcelas de erosão e em anos de precipitações médias normais e anos com precipitações acima da média e com eventos extremos. Feng et al. (2015) concluíram que as areias e silte eram os materiais mais perdidos em eventos extremos. Em contrapartida, em eventos normais, as perdas eram compostas basicamente por materiais mais finos, como silte e argila (HU et al., 2007).

Os solos da BHJ apresentam na camada superficial $(0-20 \mathrm{~cm})$ teores de argila variando de 41,3 a 49,3 \% (Tabela 3 ). Nestas parcelas mais de $70 \%$ do total de solo perdido era composto por frações de argila. O mesmo observa-se com as parcelas em solos arenosos da BHMG, onde os solos originais apresentam taxas iguais e inferiores a $16 \%$ de argila, e as perdas de solo verificadas em eventos erosivos de menor intensidade apresentaram perdas significativas das frações de argila. Tal constatação corrobora com Young e Onstad, (1978), Meyer et al. (1992) e Nunes e Cassol (2011), os quais relataram que os sedimentos produzidos nos eventos erosivos tendem a apresentar maior quantidade de partículas de menor diâmetro quando comparadas às classes texturais do solo original.

Khan et al. (2013) e Martinez-Mena et al. (1999) observaram alta mobilização de partículas mais finas em solos com maior cobertura de superfície. Assim, o desenvolvimento da cultura de cana-de-açúcar ao longo do período estudado e o consequente aumento da cobertura de solo pela vegetação também propiciou na perda de frações menores, como silte e principalmente argila (Figuras 3 e 4) em ambas as áreas de estudo.

Para ambas as áreas de estudo, as maiores perdas totais de solo, e superiores aos limites toleráveis, foram verificadas em parcelas com solo exposto, corroborando com o observado por Martinez-Mena et al. (1999) e Castillo et al. (1997) (Tabela 3). Constatou-se que a vegetação contribuiu para a redução do impacto da gota da chuva no solo e serviu como obstáculo frente a ocorrência do escoamento superficial direto. Portanto, as perdas de solo observadas junto às parcelas S1M, S2M, S1 J e S2J foram oriundas tanto do processo de destacamento das partículas pelas gotas da chuva como pelo escoamento superficial.

Tabela 3.Tolerância de perda, perdas de solo e erosividade anual registradas nas parcelas no ano experimental.

\begin{tabular}{cccc}
\hline Parcelas & $\begin{array}{c}\text { Tolerância de perda } \\
\text { - }\end{array}$ & $\begin{array}{c}\text { Perda de solo } \\
\text { En }\end{array}$ & $\begin{array}{c}\text { Erosividade anual } \\
\mathrm{MJ} \mathrm{mm} \mathrm{ha}^{-1} \mathrm{ano}^{-1}\end{array}$ \\
\hline S1M & 5,25 & 74,03 & \\
C1M & 5,25 & 49,04 & \\
S2M & 3,35 & 206,53 & 4546,89 \\
C2M & 3,35 & 84,85 & \\
P1M & 5,47 & 1,49 & \\
\hline S1J & 6,07 & 5,61 &
\end{tabular}




$\begin{array}{cccc}\text { C1J } & 6,07 & 0,8 & \\ \text { S2J } & 4,15 & 45 & 2621,08 \\ \text { C2J } & 4,15 & 2,76 & \\ \text { P1J } & 6,92 & 0,05 & \\ \text { Corrêa (2016). } & \text { Fonte: Elaborado pelos autores }\end{array}$

As perdas totais de solo nas parcelas com cana-de-açúcar foram superiores aos limites toleráveis nas parcelas $\mathrm{C} 1 \mathrm{M}$ e C2M. Tais parcelas apresentam valores superiores a $75 \%$ de areia na camada superficial e os perfis de solos apresentam texturas variando de franco arenosa a franco em declives iguais e/ou superiores a 12\% (Tabela 3).

Quando da comparação entre as parcelas de cana C1M e C2M, verifica-se que as maiores perdas em C2M (de 49 para 84,85 t ha $^{-1}$ ano-1) ocorre na mesma proporção ao incremento de areia fina das camadas superiores do solo (de 55 para $80 \%$ entre 0 e $20 \mathrm{~cm}$ ), ressaltando a maior fragilidade dos solos pelo predomínio de areia. Apesar da proteção oferecida pela cobertura vegetal frente aos processos de destacamento de partículas e transporte pelo escoamento superficial, esta não foi suficiente para que as perdas de solo observadas nos solos arenosos fossem toleráveis. Neste contexto, atenção deve ser dada quando da expansão de determinados cultivos agrícolas em áreas que naturalmente apresentam maior susceptibilidade aos processos de degradação dos solos.

Nas parcelas em cana-de-açúcar nos solos argilosos, verificou-se que as perdas neste tipo de cultivo permaneceram abaixo dos limites toleráveis. Apesar disso, na comparação entre as parcelas $C 1 \mathrm{~J}$ e $\mathrm{C} 2 \mathrm{~J}$, os menores teores de argila e maiores proporções de silte na parcela C2J, associada aos maiores declives, contribuiu para as maiores perdas de solo.

As áreas com pastagem em ambas as áreas de estudo e as áreas com canade-açúcar em solos argilosos apresentaram perdas toleráveis de solo (Tabela 3). Tal resultado demonstra que os usos estão, no geral, adequados quanto às limitações naturais de cada paisagem.

\section{CONSIDERAÇÕES FINAIS}

No estado de São Paulo verifica-se grande expansão do cultivo de cana-deaçúcar em áreas antes ocupadas por coberturas de maior proteção do solo. Este é o caso da BHMG, onde a expansão da cultura de cana-de-açúcar se deu em áreas anteriormente ocupadas por pastagens. A mudança no uso da terra acarretou em perdas anuais de solos superiores aos limites toleráveis. As perdas nas parcelas com cana-de-açúcar em solos arenosos foram 13 e 24 vezes superiores aos limites toleráveis respectivamente para as parcelas C1M e C2M. Tal resultado, demonstra que o processo de degradação destes solos é eminente.

A erosividade foi um fator que alterou a granulometria do material erodido junto aos solos arenosos e junto a solos argilosos, descobertos e localizados em declives superiores a $11 \%$. Os solos argilosos, quando localizados em baixas declividades e com cobertura vegetal, por serem mais estruturados, não apresentaram mudança no padrão granulométrico do material erodido com o aumento da erosividade.

Em ambas as áreas de estudo, com solos arenosos e argilosos, observaramse perdas significativas de argila quando da comparação com a textura do solo original. Tais resultados sinalizam que as frações mais reativas dos solos estão sendo 
removidas e transportadas mais intensamente. No entanto, a perda acelerada destas frações observadas em parcelas com culturas temporárias demonstra o processo de depauperamento dos solos, especialmente nas parcelas com solos arenosos, cujas perdas de solos foram superiores aos limites toleráveis e os materiais perdidos eram compostos por frações mais finas e reativas que a textura do solo.

As perdas acentuadas das frações coloidais dos solos estudados indicam que a região pode sofrer com a diminuição da produção agrícola, contaminação dos corpos hídricos, aumento dos gastos com insumos agrícolas bem como a rápida degradação e futuro abandono destas áreas. É neste sentido que maior atenção deve ser dada quanto às mudanças no uso da terra e na expansão de culturas temporárias em áreas antes ocupadas por cobertura permanente e de maior proteção.

\section{AGRADECIMENTOS}

À Fundação de Amparo à Pesquisa do Estado de São Paulo (FAPESP), pela bolsa de doutorado concedida e pelo apoio financeiro por meio do auxílio à Pesquisa; à Prefeitura Municipal de Ipeúna e à Coordenadoria de Assistência Técnica Integral CATI, pelo apoio e suporte às atividades de campo e as Usinas de Açúcar e Álcool, Granelli e grupo Raízen, pelo apoio e concessão das áreas para a implantação dos experimentos.

\section{REFERÊNCIAS BIBLIOGRÁFICAS}

ASADI, H.; GHADIRI, H.; ROSE, C.W.; ROUHIPOUR, H. Interrill soil erosion processes and their interaction on low slopes. Earth Surface Processes Landform, n. 32, p. 711-724, 2007. DOI: 10.1002/esp.1426.

BERTOL, I.; ENGEL, F.; MAFRA, A.L.; BERTOL, O.J.; RITTER, S. Phosphorus, potassium and organic carbon concentrations in runoff under different soil tillage systems during soybean growth. Soil and Tillage Research, v. 94, n. 1, p. 142-150, 2007. DOI: 10.1016/j.still.2006.07.008.

BERTONI, J.; LOMBARDI NETO, F. Conservação do solo. 7. ed. São Paulo: Editora Ícone, 2010.

CABEDA, M. S. V. Computation of storm EI Values. West Lafayette: Purdue University, $1976.6 \mathrm{p}$.

CAMARA, M. R. G.; CALDARELLI, C. E. Expansão canavieira e o uso da terra no estado de São Paulo. Estudos Avançados, v. 30, n. 88, p. 93-116, 2016. DOI: 10.1590/s0103-40142016.30880008.

CARVALHO, N. O.; FILIZOLA JÚNIOR, N.P.; SANTOS, P.M.C.; LIMA, J.E.F.W. Guia de práticas sedimentométricas. Brasília: ANEEL. 2000. 154p.

CASSOL, E. A.; LEVIEN, R.; I. ANGHINONI.; BADELUCCI, M. P. Perdas de nutrientes por erosão em diferentes métodos de melhoramento de pastagem nativa no Rio Grande do Sul. Revista Brasileira de Ciência do Solo, v. 26, n. 3, p. 705-712, 2002. DOI: 10.1590/S0100-06832002000300015. 
CASTILLO, V.M.; MARTINEZ-MENA, M.; ALBALADEJO, J. Runoff and soil loss response to vegetation removal in a semiarid environment. Soil Science Society of America, v. 61, n. 4, p. 1116-1121, 1997. DOI: 10.2136/sssaj1997.03615995006100 040018x.

COGO, N.P. Uma contribuição à metodologia de estudo das perdas de erosão em condições de chuva natural. I. Sugestões gerais, medição dos volumes, amostragem e quantificação de solo e água da enxurrada. $1^{\text {a }}$ aproximação. In: Encontro Nacional de Pesquisa sobre Conservação do Solo, 2., 1978, Passo Fundo. Anais... Passo Fundo: Empresa Brasileira de Pesquisa Agropecuária, 1978. p.75-98.

COGO, N. P.; LEVIEN, R.; SCHWARZ, R. A. Perdas de solo e água por erosão hídrica influenciadas por métodos de preparo, classes de declive e níveis de fertilidade do solo. Revista Brasileira de Ciência do Solo, v. 27, n. 4, p. 743-753, 2003. DOI: 10.1590/S0100-06832003000400019.

CORRÊA, E. A.; MORAES, I. C. ; PINTO, S. A. F. Estimativa da erodibilidade e tolerância de perda de solos oriundos de arenitos e argilitos da região centro-leste paulista. Geociências (São Paulo. Online), v. 34, p. 848-860, 2015.

CORRÊA, E. A. Perdas de solo e índices de vegetação: proposta metodológica para a determinação do fator C (MEUPS) em pastagens e cana-de-açúcar. Tese (Doutorado em Geografia) - Instituto de Geociências e Ciências Exatas, Universidade Estadual Paulista, Rio Claro, 2016. 187p.

CORRÊA, E. A; MORAES, I. C.; LUPINACCI, C. M.; PINTO, S. A. F. Influência do cultivo de cana-de-açúcar nas perdas de solo por erosão hídrica em cambissolos no estado de São Paulo. Revista Brasileira de Geomorfologia, v. 19, n. 2, 2018. DOI: http://dx.doi.org/10.20502/rbg.v19i2.1303.

DENARDIN, J. E. Erodibilidade do solo estimada por meio de parâmetros físicos e químicos. Tese (Doutorado em Solos e Nutrição de Plantas) - Escola Superior de Agricultura Luiz de Queiroz, Universidade de São Paulo, Piracicaba, 1990. 113p.

EASTERLING, D.R.; MEEHL, G.A.; PARMESAN, C.; CHANGNON, S.A.; KARL, T.R.; MEARNS, L.O. Climate extremes: Observations, modeling, and impacts. Science, v. 289, n. 22, p.2068-2074, 2000. DOI: 10.1126/science.289.5487.2068.

EMBRAPA - Empresa Brasileira de Pesquisa Agropecuária. Centro Nacional de Pesquisa de Solos. Manual de métodos de análise de solos. 2 ed. Rio de Janeiro, 1997, $212 \mathrm{p}$.

ESTRANY, J.; GARCIA, C.; BATALLA, R.J. Hydrological response of a small mediterranean agricultural catchment. Journal of Hydrology, v. 380, p. 180-190, 2010. DOI: 10.1016/j.jhydrol.2009.10.035.

FALCÃO SOBRINHO, J.; FALCÃO, C. L. C. Erosão em Ambiente Fluvial: Técnicas de Monitoramento Associadas ao Relevo e a Vegetação. In: XI Simpósio Brasileiro de Geografia Física Aplicada, 11., 2005, São Paulo. Anais... São Paulo, 2005. 
FENG, Q.; GUO, X.D.; ZHAO, W.W.; QIU, Y.; ZHANG, X. A comparative analysis of runoff and soil loss characteristics between "extreme precipitation year" and "normal precipitation year" at the plot scale: a case study in the Loess Plateau in China. Water, v. 7 , n. 7, p. 3343-3366, 2015. DOI: 10.3390/w7073343.

FOSTER, G.R.; LANE, L.J.; NOWLIN, J.D.; LAFLEN, J.M.; YOUNG, R.A. Estimating erosion and sediment yield and field-sized areas. Transactions of the ASAE, v. 24, n. 5, p. 1253-1262, 1981. DOI: 10.13031/2013.34429.

FOSTER, G. R.; YOUNG, R. A.; RONKENS, M. J. M.; ONSTAD, C. A. Processes of soil erosion by water. In: FOLLETT F. R, STEWART B. A (editors). Soil erosion and crop productivity. Madison (WI): American Society of Agronomy and Crop Science Society of America. 1985. p 137-62.

GAO, C.; ZHU, J.; ZHU, J.; HOSEN, Y.; ZHOU, J.; WANG, D.; WANG, L.; DOU, Y. Effects of extreme rainfall on the export of nutrients from agricultural land. Acta Geogr. Sin, v.60, p. 991-997, 2005.

GARCÍA-RUIZ, J.M.; BEGUERÍA, S.; NADAL-ROMERO, E.; GONZÁLEZ-HIDALGO, J. C.; LANA-RENAULT, N., SANJUÁN, Y. A meta-analysis of soil erosion rates across the world. Geomorphology, v. 239, n.15, p. 160-173, 2015. DOI: 10.1016/j.geomorph.2015.03.008.

GROISMAN, P.Y.; KNIGHT, R.W.; EASTERLING, D.R.; KARL, T.R.; HEGERL, G.C.; RAZUVAEV, V.N. Trends in intense precipitation in the climate record. Journal of Climate, v.18, p. 1326-1350, 2005. DOI: 10.1175/JCLI3339.1.

GUERRA, A. J. T. Processos erosivos nas encostas. In: CUNHA, S.B.; GUERRA, A. J. T. Geomorfologia - Exercícios, Técnicas e Aplicações. $2^{\circ}$ ed. Rio de Janeiro: Bertrand Brasil, Rio de Janeiro, 2005. p. 139-155.

HATFIELD, J.L. Precision agriculture and environmental quality: challenges for research and education. 2000. Documento online: http://www.arborday. org/PROGRAMS/papers/PrecisionAg.html, acesso em 10/2020.

HU, H.; HONG, T.; MA, Y.; LIU, K. Study on soil and sediment particle size distribution and nutrient loss. Journal of Soil and Water Conservation, n. 21, p. 26-29, 2007.

IPT - Instituto de Pesquisas Tecnológicas do estado de São Paulo. Mapa Geomorfológico do Estado de São Paulo. São Paulo: IPT, 1981.

IPT - Instituto de Pesquisas Tecnológicas do estado de São Paulo. Mapa Geomorfológico do Estado de São Paulo. São Paulo: IPT, 1999.

JIN, K.; CORNELIS, W.M.; GABRIELS, D.; BAERT, M.; WU, H.J.; SCHIETTECATTE, W.; CAI, D.X.; DE NEVE, S.; JIN, J.Y.; HARTMANN, R.; HOFMAN, G. Residue cover and rainfall intensity effects on runoff soil organic carbon losses. Catena, v. 78, p. 8186, 2009. DOI: 10.1016/j.catena.2009.03.001. 
KHAN, F.; HAYAT, Z.; AHMAD, W.; RAMZAN, M.; SHAH, Z.; SHARIF, M.; MIAN, I.A.; HANIF, M. Effect of slope position on physico-chemical properties of eroded soil. Soil Environ., v.32, p. 22-28, 2013.

KIANI-HARCHEGANI, M.; SADEGHI, S.H.R.; ASADI, H. Changeability of concentration and particle size distribution of effective sediment in initial and mature flow generation conditions under different slops and rainfall intensities. Iranian Journal of Watershed Engineering and Management, v. 9, n. 2, p. 205-216, 2017. DOI: 10.22092/IJWMSE.2017.109726.

LI, G.L.; PANG, X.M. Difference in organic carbon contents and distributions in particlesize fractions between soil and sediment on the Southern Loess Plateau, China. Journal of Mountain Science, v. 11, p. 717-726, 2014.

LOMBARDI NETO, F. Rainfall erosivity - its distribution and relationship with soil loss at Campinas, 1977. Dissertação (Master of Sciente) - Purdue University, West Lafayette, 1977.

MANO, V.; NEMERY, J.; BELLEUDY, P.; POIREL, A. Assessment of suspended sediment transport in four alpine watersheds (France): Influence of the climatic regime. Hydrological . Process, n.23, p. 777-792, 2009. DOI: 10.1002/hyp.7178.

MARTINEZ-MENA, M.; ALVAREZ ROGEL, J.; ALBALADEJO, J.; CASTILLO, V. M. Influence of vegetal cover on sediment particle size distribution in natural rainfall conditions in a semiarid environment. Catena, n.38, p. 175-190, 1999. DOI: 10.1016/S0341-8162(99)00073-9.

MEYER, L.D.; LINE, D.E.; HARMON, W.C. Size characteristics of sediment from agricultural soils. Journal of Soil and Water Conservation, n. 47, p.107-111, 1992. MEYER, L.D.; HARMON, W.C.; MCDOWELL, L.L. Sediment sizes eroded from crop row side slopes. Transactions of the ASAE, n. 23, p.891-898, 1980. DOI: 10.13031/2013.34682.

MEYER, L.D.; HARMON, W.C. Susceptibility of agricultural soils to interrill erosion. Soil Sci. Soc. Am. J., v. 48, p. 1152-1157, 1984. DOI: https://doi.org/10. 2136/sssaj1984.03615995004800050040x.

MOHAMMADKHAN, S.; AHMADI, H.; JAFARI, M. Relationship between soil erosion, slope, parent material, and distance to road (Case study: Latian Watershed, Iran). Arabian Journal Geoscience, n.4, p.331-338, 2011. DOI: 10.1007/s12517-0100197-z.

MORAES, I.C. Avaliação dos modelos de predição da erosão hídrica MEUPS e WEPP: contribuição em bacias hidrográficas. Tese (Doutorado em Geografia) Instituto de Geociências e Ciências Exatas, Universidade Estadual Paulista, Rio Claro, 2016. $191 \mathrm{p}$.

NUNES, M.C.M.; CASSOL, E.A. Produção de sedimentos pela erosão em entressulcos em três Latossolos do Rio Grande do Sul. Revista Brasileira de 
Engenharia Agrícola e Ambiental, v. 15, p.541-547, 2011. DOI: 10.1590/S141543662011000600001.

PENTEADO, M.M. Geomorfologia do setor centro-ocidental da depressão periférica paulista. Instituto de Geografia, Universidade de São Paulo, São Paulo, Série Teses e Monografias 22, 1976. 86 p.

PEREIRA, L. H.; PINTO, S.A.F. Utilização de imagens aerofotográficas no mapeamento multitemporal do uso da terra e cobertura vegetal na bacia do rio Corumbataí - SP, com osuporte de sistemas de informações geográficas. In: Simpósio Brasileira de Sensoriamento Remoto, 13., 2007, Florianópolis (SC). Anais..., São José dos Campos - SP: INPE. Anais XIII SBSR, 2007, p. 1321-1328.

POLYAKOV, V.; LAL, R. Modeling soil organic matter dynamics as affected by soil water erosion. Environmental International, v. 30, p. 547-556, 2004. DOI: 10.1016/j.envint.2003.10.011.

RODRIGO-COMINO, J.; SEEGERB, M.; ISERLOHB, T.; GONZÁLEZ, J. M. S.; RUIZSINOGAA, J. D.; RIESB, J. B. Rainfall-simulated quantification of initial soil erosion processes in sloping and poorly maintained terraced vineyards - Key issues for sustainable management systems. Science of The Total Environment, v. 660, p. 1047-1057, 2019. DOI: 10.1016/j.scitotenv.2018.12.451.

SADEGHI, S. H.; HARCHEGANI, M. K.; HOSSEIN ASADI, H. Variability of particle size distributions of upward/downward splashed materials in different rainfall intensities and slopes, Geoderma, v. 290, p. 100-106, 2017. DOI: 10.1016/j.geoderma.2016.12.007.

SANTOS, H.G.; JACOMINE, P.K.T.; ANJOS, L.H.C.; OLIVEIRA, V.A.; LUMBRERAS, J.F.; COELHO, M.R.; ALMEIDA, J.A.; CUNHA, T.J.F.; OLIVEIRA, J.B. Sistema Brasileiro de Classificação de Solos. 5.ed. Brasília: Embrapa, 2018.

SCHIETTECATTE, W.; GABRIËLS, D.; CORNELIS, W.; HOFMAN, G. Enrichment of organic carbon in sediment transport by interrill and rill erosion processes. Soil Science Society of America Journal, v. 72, p. 50-55, 2008. DOI: 10.2136/sssaj2007.0201.

SUZUKI, L. E. A. S.; MATIESKI, T.; STRIEDER, G.; PAULETTO, E. A; BORDINS. S.; LIMA, L. S; COLLARES, G. C.; DAIPRÁ, M. Perdas de solo por erosão hídrica e granulometria do Material erodido em propriedades agrícolas. In: X Encontro Nacional de Engenharia de Sedimentos, 2012, Foz do Iguaçu-PR. Anais... Foz do Iguaçu-PR, 2012.

TAVARES, A.C. Mudanças climáticas. In: VITTE, A.C.; GUERRA, A.J. (Orgs). Reflexões sobre a geografia física no Brasil. Rio de Janeiro: Bertrand Brasil, 2004.

VEIGA FILHO, A. A.; SOUZA, M. V. M.; MARTINB, N. B.; YANAGUISH, C. T.; MATSUNAGA, M. Análise de investimentos em adoção de tecnologias e conservação do solo no estado de São Paulo. Agricultura em São Paulo, v. 39, n. 1, p. 133-154, 1992. 
VOLK, L.B.S.; COGO, N.P. Relações entre tamanho de sedimentos erodidos, velocidade da enxurrada, rugosidade superficial criada pelo preparo e tamanho de agregados em solo submetido a diferentes manejos. Revista Brasileira de Ciências do Solo, v. 33, p. 1459-1471, 2009. DOI: 10.1590/S0100-06832009000500036.

WANG, L.; SHI, Z.H. Size selectivity of eroded sediment associated with soil texture on steep slopes. Soil Science Society of America Journal, v. 79, p. 917-929, 2015. DOI: 10.2136/ sssaj2014.10.0415.

WARRINGTON, D. N.; MAMEDOV, A. I.; BHARDWAJ, A., K, LEVY, G. J. Primary particle size distribution of eroded material affected by degree of aggregate slaking and seal development. European Journal of Soil Science, n. 60, p. 84-93, 2009. DOI: 10.1111/j.1365-2389.2008.01090.x.

WISCHMEIER, W. H. A rainfall erosion index for a universal soil-loss equation. Soil Science Society of America Proceedings, v.23, p.246-249, 1959.

WISCHMEIER, W.H.; SMITH, D.D. Predicting rainfall erosion losses: a guide to conservation planning. Washington: United States Department of Agriculture, 1978, 57 p. (Agriculture Handbook, n. 537).

YANG, W.G.; ZHENG, F.L.; HAN, Y. Effects of topography on spatial distribution of soil erosion and deposition on hillslope in the typical of black soil region. Acta Pedologica Sinica, v. 53, p. 572-581, 2016. DOI: 10.11766/trxb201508240314.

YOUNG, R. A.; ONSTAD, C. A. Characteristics of rill and inter-rill eroded soil. Trans, am. Soc. agric. Engrs., v.21, p. 1126-1130, 1978.

ZHANG, G.H.; LIU, G.B.; WANG, G.L.; WANG, Y. X. Effects of vegetation cover and rainfall intensity on sediment-bound nutrient loss, size composition and volume fractal dimension of sediment particles. Pedosphere, n. 21, 676-684, 2011. DOI: 10.1016/S1002-0160(11)60170-7. 